\title{
Moving Forward on Remote Sensing of Soil Salinity at Regional Scale
}

\author{
Elia Scudiero ${ }^{1,2 *}$, Dennis L. Corwin ${ }^{2}$, Ray G. Anderson ${ }^{2}$ and Todd H. Skaggs ${ }^{2}$ \\ ${ }^{1}$ Department of Environmental Sciences, University of California, Riverside, Riverside, CA, USA, ${ }^{2}$ United States Salinity \\ Laboratory, United States Department of Agriculture-Agricultural Research Service, Riverside, CA, USA
}

\section{OPEN ACCESS}

Edited by:

Christophe Darnault,

Clemson University, USA

Reviewed by:

Nabeel Khan Niazi,

University of Agriculture Faisalabad,

Pakistan

Wieslaw Fialkiewicz,

Wroclaw University of Environmental and Life Sciences, Poland

*Correspondence:

Elia Scudiero

elia.scudiero@ars.usda.gov;

scudiero@dmsa.unipd.it

Specialty section:

This article was submitted to Soil Processes

a section of the journal

Frontiers in Environmental Science

Received: 05 August 2016

Accepted: 23 September 2016

Published: 06 October 2016

Citation:

Scudiero E, Corwin DL, Anderson RG

and Skaggs TH (2016) Moving

Forward on Remote Sensing of Soil

Salinity at Regional Scale.

Front. Environ. Sci. 4:65.

doi: 10.3389/fenvs.2016.00065
Soil salinity undermines global agriculture by reducing crop yield and impairing soil quality. Irrigation management can help control salinity levels within the soil root-zone. To best manage water and soil resources, accurate regional-scale inventories of soil salinity are needed. The past decade has seen several successful applications of soil salinity remote sensing. Two salinity remote sensing approaches exist: direct assessment based on analysis of surface soil reflectance (the most popular approach) and indirect assessment of root-zone (e.g., 0-1 m) soil salinity based on analysis of crop canopy reflectance. In this perspective paper, we call on researchers and funding agencies to pay greater attention to the indirect approach because it is better suited for surveying agriculturally important lands. A joint effort between agricultural producers, irrigation specialists, environmental scientists, and policy makers is needed to better manage saline agricultural soils, especially because of projected future water scarcity in arid and semi-arid irrigated areas. The remote sensing community should focus on providing the best tools for mapping and monitoring salinity in such areas, which are of vital relevance to global food production.

Keywords: soil salinity, remote sensing, soil quality, agriculture, irrigation

\section{INTRODUCTION}

Soil salinity is a major threat to crop production and sustainable agriculture (FAO and ITPS, 2015). Salinity can cause reduced plant growth, reduced yields, and in severe cases, crop failure. In irrigated agriculture, especially in arid and semi-arid areas, the buildup of salts in the soil profile is driven by evapotranspiration processes that remove water from soil pores while leaving salts behind. Accumulation of salts can be avoided by applying excess irrigation water, such that salts are leached below the root-zone (Letey et al., 2011). Unfortunately, water shortages and droughts in arid and semi-arid areas are likely to become more frequent and severe in the future (Barnett et al., 2008; Cayan et al., 2010), thus increasing soil salinity threats. Monitoring soil salinity at regional and state levels is essential for identifying and understanding drivers and trends in soil salinity, and for developing mitigation strategies and management plans.

Current estimates are that nearly one billion ha of land are salt-affected. Globally, about $20 \%$ of the $\sim 300$ million ha of irrigated farmland is estimated to be affected by salinity. More than half of all salt-affected irrigated agricultural lands are found in four countries (China, India, Pakistan, and United States; FAO and ITPS, 2015). However, farmland data at the level of individual countries is sparse and of dubious quality (Lobell, 2010).

The number of publications focusing on soil salinity assessment with remote sensing has increased considerably in the past decade. According to Thompson Reuters' Web of Science, the annual average number of scientific publications with the combined topics of "remote sensing" and 
"soil salinity" increased from 9.7 through 1996-2005, to 33.9 through 2006-2015. The literature includes both "field scale" and "regional scale" applications. Salinity remote sensing has been used successfully at the field scale (e.g., Goldshleger et al., 2013), although proximal electromagnetic survey measurements are a much more established technology in that problem domain (see Corwin et al., 2012). The focus of the current perspective paper is the regional scale $\left(10^{2}-10^{5} \mathrm{~km}^{2}\right)$, where remote sensing of soil salinity is problematic because salinity spatial variability is influenced by a number of multi-scale agronomic, hydrological, pedogenic, topographical, meteorological, anthropogenic, and edaphic factors. Generally, two remote sensing approaches have been used to map soil salinity at regional scale. The most established approach uses spatial analyses of surface (bare-) soil reflectance. The other obtains an indirect assessment of soil salinity through analysis of crop canopy reflectance. Since crops and crop reflectance are affected by salinity conditions throughout the root-zone (e.g., $0-1 \mathrm{~m}$ ), the latter indirect approach in essence senses the salinity of the entire rootzone. Research on canopy reflectance analysis for regional scale salinity mapping started showing promising results only in the last 10 years and has not produced many peer-reviewed publications. We call on fellow researchers and funding agencies to prioritize the indirect approach because of its greater relevance to agriculture. This paper provides an overview of the (direct) surface salinity and (indirect) root-zone salinity assessment approaches, a short review of milestone papers on root-zone salinity assessment, a description of the limitations of each approach, and suggests directions for future opportunities.

\section{SURFACE SOIL SALINITY}

Surface soil salinity applications have been explored extensively, as reviewed by Metternicht and Zinck (2003), Ben-Dor et al. (2008), and Allbed and Kumar (2013). The surface approach delivers reasonably accurate spatial predictions of soil salinity (e.g., Fan et al., 2015). Accumulation of salts at the soil surface can result in loss of soil quality and increase erosion. Salt crusts have reflectance properties that are very different from those of non-salt-affected soils (Mougenot et al., 1993), making them easy to identify and classify (e.g., by using fuzzy classification and microwave measurements; see Metternicht, 1998). When salt efflorescence is partial, especially at coarse resolution, different soil type (e.g., texture, color) and roughness, presence of sparse vegetation, and surface water content can have confounding effects on salinity estimations. However, these effects can be accounted for, as presented by Xu et al. (2016).

Unfortunately, monitoring salinity at the soil surface has limited relevance in agro-environmental applications because plant growth and yield are negatively influenced by salinity within the entire root-zone. Often, there is not a direct correlation between surface and root-zone soil salinity (e.g., Zare et al., 2015), making surface assessments of soil salinity agriculturally irrelevant except for evaluation of plant germination. This is a significant issue because in irrigated agriculture salinity generally accumulates deeper in the root zone.

\section{ROOT-ZONE SOIL SALINITY}

Canopy reflectance can be used as a proxy for crop status, in particular, for monitoring plant-soil relationships. Under salinity stress, crop canopy reflectance increases in the visible range (e.g., $450-700 \mathrm{~nm}$ ) and decreases in the near-infrared (e.g., $770-900 \mathrm{~nm}$ ) range. However, remote sensing of salinity based on vegetation analysis over large areas has often returned unsatisfactory results. This is because other stress sources (e.g., water stress, pests) trigger very similar responses in canopy reflectance. Furthermore, different crops have different phenology and reflectance properties, making it difficult to model plant-soil interactions at the regional scale.

With their pioneering papers, Lobell et al. (2007) and Lobell et al. (2010) showed that temporal analysis of canopy reflectance is the key to successful regional scale soil salinity mapping. Lobell et al. (2007) hypothesized that most stressors (e.g., pests, mismanagement, diseases) are transient in time. However, under similar farming practices, average salinity in the root-zone remains relatively stable over multiple years (i.e., 5-7 years). They preliminarily tested this hypothesis over 182 fields in the Colorado River Delta region, Mexico, noting that consistently low yields were an indicator of high root-zone salinity. In the paper by Lobell et al. (2010) this hypothesis was tested showing that the relationship between soil salinity in the Red River Valley (USA) and summer average values of the Enhanced Vegetation Index (EVI) obtained from the Moderate Resolution Imaging Spectro radiometer (MODIS) instruments (NASA Aqua and Terra satellites) changed substantially from year to year. Using 7-year average summer EVI value significantly improved the EVI-salinity relationship. The multi-year data masked the effect of other stress types on canopy reflectance. Additionally, they observed that lands farmed with irrigated annual crops have different reflectance properties than fallow and barren rain-fed land.

Wu et al. (2014) and Scudiero et al. (2015) have validated and improved the approach of Lobell et al. (2010). Wu et al. (2014) used multi-year maxima of vegetation indices to map soil salinity in Iraq. They used a multi-scale platform consisting of MODIS and Landsat 7 (USGS and NASA, USA) imagery because MODIS data alone would provide estimations too coarse for agricultural applications. Scudiero et al. (2015) used the multiyear vegetation index maxima approach to map soil salinity over farmlands of the western San Joaquin Valley in the USA. By including the presence or absence of a crop and meteorological information (temperature and rainfall) in their spatial prediction model, Scudiero et al. (2015) calibrated Landsat 7 data to soil salinity with unprecedented accuracy in the $0<\mathrm{EC}_{\mathrm{e}}<20 \mathrm{dS}$ $\mathrm{m}^{-1}$ range (i.e., at levels where most crops can grow without total failure), where $\mathrm{EC}_{\mathrm{e}}$ is soil salinity measured as electrical conductivity of the saturated soil extract (in $\mathrm{dS}^{-1}$ ).

\section{Ground-Truthing is Essential}

To avoid erroneous predictions, spatial and temporal extrapolations should always be minimized. Vegetation indices, such as the Normalized Difference Vegetation Index (NDVI), can be used to map salinity, but are generally not stress specific: they simply measure plant status. Therefore, they need 
to be calibrated locally. Extensive ground-truth surveys are necessary. Ideally, when selecting a ground-truth dataset, one should sample according to the frequency distribution of the target variable, which is impossible to know a priori. As a best guess for capturing the variability of soil salinity, Lobell et al. (2010) selected ground-truth sites according to the frequency distribution of MODIS data. To increase the extent of surveyed land in a cost-effective manner, local salinity maps can be created using near-ground electromagnetic surveys and apparent soil electrical conductivity directed soil sampling (Corwin et al., 2012), as done by Lobell et al. (2010), Wu et al. (2014), and Scudiero et al. (2015).

\section{Spatial Modeling}

Typically, this kind of modeling follows the directives for digital soil mapping delineated by McBratney et al. (2003). The ground-truth data is used to establish a statistical relationship with selected covariates to estimate soil salinity at unsampled locations. Remote sensing data is used as the main explanatory variable, and several co-variables can be added (e.g., environmental, management, meteorological, landscape position) to improve the remote sensing predictions of soil salinity. Linear modeling (either additive or multiplicative, see Tian et al., 2013) is a viable means of regional-scale soil mapping. Other modeling approaches include artificial neural networks, geostatistics, and support vector analysis, just to mention a few. Any selected modeling technique should be robust for the entire area of study. Of particular noteworthiness is that the coefficient of determination $\left(R^{2}\right)$ is often not a good measure of map accuracy (Scudiero et al., 2015). For example, consider the case where prediction errors for a linear model with $R^{2}=0.85$, based on a ground-truth dataset of salinity with $\mathrm{EC}_{e}$ ranging from 0 to $120 \mathrm{dS} \mathrm{m}^{-1}$, are likely to be significantly higher than those for a regression with $R^{2}=0.65$ modeling $\mathrm{EC}_{\mathrm{e}}$ in the $0-$ $30 \mathrm{dS} \mathrm{m}^{-1}$ range. Model parameterization should put particular focus on reducing prediction errors (i.e., residual errors) at the low salinity range (e.g., $0<\mathrm{EC}_{\mathrm{e}}<8 \mathrm{dS} \mathrm{m}^{-1}$ ), which is the most important range for agricultural management. Model accuracy should be discussed with respect to its prediction errors at unknown locations. This can be done through (spatiallyindependent) resampling (e.g., cross validation) and/or by independent validation.

\section{Limitations and Research Gaps Are Future Research Challenges}

The above reviewed publications represent clear steps forward in remote sensing of soil salinity of agricultural soils at the regional scale. However, there are many limitations and research gaps that currently characterize this approach, including:

- Uncertainty of predictions at low salinity values. At low salinity levels, the growth of many crops is not significantly influenced (Maas and Hoffman, 1977), making it difficult to assess the underlying soil salinity through canopy reflectance. This issue could be addressed by considering the specific reflectance properties of each crop present in a region, as explored by Zhang et al. (2011). However, the parameterization of crop-specific coefficients need to be regionalized; i.e., the crop-salinity interactions should be fully represented in the ground-truth dataset. In the USA, online databases like the Cropland Data Layers (Han et al., 2012) can be helpful for the purpose of crop-specific modeling. Additionally, when salinity is not the only factor consistently limiting plant growth, the resulting salinity model will be returning erroneous predictions. This issue may be resolved by the use of high resolution covariates for soil properties. Scudiero et al. (2015) indicated that high resolution soil texture information would significantly improve their model's performance. If such information was available, then the soil texture-salinity interactions should be fully represented in the ground-truth dataset.

- Halophyte reflectance properties are problematic. Halophyte (salt-tolerant plants) growth is optimal at fairly high soil salinity (e.g., $8-12 \mathrm{dS} \mathrm{m} \mathrm{m}^{-1}$ ), but reduced when salinity is too high or too low (BOSTID, 1990). As observed by Scudiero et al. (2015) and Zhang et al. (2015) this affects remote sensing predictions of soil salinity, as low plant performances (e.g., low NDVI scores) can be caused by either low or very-high soil salinity values.

- Published work does not focus on perennial tree crops. Reflectance over orchards are a mixture of bare-soil (or inter raw cover crop) and tree canopy reflectance. Moderately high resolution imagery (e.g., Landsat) often returns unrealistically low NDVI scores because of this (Scudiero et al., under review). Future research should focus on the use of higher resolution remote sensing data, or on the use of scaling coefficients for better salinity estimations over orchards.

- Selection of satellite products. Multi-spectral vegetation indices were successfully used to monitor salinity by Lobell et al. (2010), Wu et al. (2014), Scudiero et al. (2015), and Zhang et al. (2015) but there might be room for improvement if hyper-spectral visible and (near) infrared data (Zhang et al., 2011) were used for the same analyses. Moreover, the addition to the analyses of other satellite data, such as thermal (Wu et al., 2014), should improve salinity assessment models. The spatial and temporal resolution of satellite data may play an important role in model performance too. Very high spatial resolution (e.g., $1 \times 1 \mathrm{~m}$ ) imagery is ideal for masking out nontarget features (e.g., water-bodies, roads) from the produced soil maps. However, correlation between soil properties and satellite data might be optimal at coarser resolutions (Gomez et al., 2015; Miller et al., 2015). Scudiero et al., under review gave a practical example of this. They showed the influence of resolution (from $2 \times 2$ to $100 \times 100 \mathrm{~m}$ ) upon the correlation between multi-temporal maximum EVI from WorldView 2 (Digital Globe, Colorado, USA) and soil salinity over a 34ha fallow field in California, USA. As resolution got coarser (by resampling), the relationship strengthened, reaching a maximum at $20 \times 20 \mathrm{~m}$. The strength of the correlation between EVI and salinity then decreased steadily as block support increased. Preliminary studies on optimal spatial resolution to be employed for a specific study area are advised before committing to a specific satellite sensor. High 
temporal resolution is very important when building a time series of vegetation indices. Very high temporal resolutions allow for semi-continuous monitoring of crop performance throughout different phenological stages, as shown by Zhang et al. (2015), which could notably improve salinity predictions. Unfortunately, high temporal resolution often comes with low spatial resolution (Mulla, 2013). Future research should focus on multi-spatial (e.g., Wu et al., 2014) and multi-temporal resolution studies to see if current salinity assessment models can be improved. Other covariates (e.g., ground water quality data, landscape position) that are known to influence crop growth at a given study region should be explored in future studies.

- Approximating a regional depth for the root-zone is erroneous. Different crops have different root depth of penetration. Despite this common knowledge, a common root-zone area was estimated by Lobell et al. (2010) in the Red River Valley, USA (0-0.9 and $0-1.5 \mathrm{~m})$, by $\mathrm{Wu}$ et al. (2014) in central Iraq $(0-1.5 \mathrm{~m})$, and by Scudiero et al. (2015) in the San Joaquin Valley, CA, USA (0$1.2 \mathrm{~m})$. Future research should focus on better defining regional values for root-zone depth, perhaps providing cropspecific depth estimates to provide more accurate salinity maps.

- The produced salinity maps are only a snapshot in time of average root-zone salinity. It may be legitimate to assume that average root-zone salinity remains fairly constant within a short number of years (e.g., 5-7 years) as proposed by Lobell et al. (2007). However, within a single season, salts redistribute fairly dynamically within the vertical soil profile because of evapotranspiration and irrigation/precipitation. At the moment, multi-temporal analysis of remote sensing imagery cannot capture such vertical variations. Moreover, none of the cited research studied short-term (1-2 years) average root-zone salinity changes due to abrupt land-use and/or irrigation practice changes. Such changes are known to be sizeable and fast (Corwin, 2012).

\section{REFERENCES}

Allbed, A., and Kumar, L. (2013). Soil salinity mapping and monitoring in arid and semi-arid regions using remote sensing technology: a review. Adv. Remote Sens. 2, 373. doi: $10.4236 /$ ars.2013.24040

Barnett, T. P., Pierce, D. W., Hidalgo, H. G., Bonfils, C., Santer, B. D., Das, T., et al. (2008). Human-induced changes in the hydrology of the western United States. Science 319, 1080-1083. doi: 10.1126/science. 1152538

Ben-Dor, E., Metternicht, G., Goldshleger, N., Mor, E., Mirlas, V., and Basson, U. (2008). "Review of remote sensing-based methods to assess soil salinity," in Remote Sensing of Soil Salinization: Impact on Land Management, eds G. Metternicht and J. A. Zaid (Boca Raton, FL: CRC Press), $39-56$.

BOSTID (Board on Science and Technology for International Development) (1990). Saline Agriculture Salt-Tolerant Plants for Developing Countries. Washington, DC: National Academy Press.

Cayan, D. R., Das, T., Pierce, D. W., Barnett, T. P., Tyree, M., and Gershunov, A. (2010). Future dryness in the southwest US and the hydrology of the early 21st century drought. Proc. Natl. Acad. Sci. U.S.A. 107, 21271-21276. doi: 10.1073/pnas.0912391107

\section{CONCLUSIONS}

Some of the most crop productive areas of the world occur in water-scarce regions where salinization of soils can be a concern. The sustainability of irrigation practices must be preserved in such areas because of the expected future increases in food demand. Unfortunately, the frequency and duration of droughts are likely to increase in arid and semi-arid regions due to global climate change. Subsequently, water resources must be utilized wisely to assure crop production and maintain soil quality. We believe that mapping soil salinity at the regional scale should be a priority in such areas. Mapping salinity only at the soil surface is not sufficient since for irrigated agriculture salinity is "hidden" below the surface where crop roots take up water. We invite scientists to focus more on indirect assessment of rootzone soil salinity through multi-temporal canopy reflectance studies. This remote sensing approach is relatively young (ca. 10 years) and has seen some successful applications, but still has limitations and considerable room for improvement. Monitoring mid-term (e.g., 5-10 years) soil salinity changes can help understand the trends and drivers of soil salinity. In particular, salinity maps and information on land use and agronomic management can help monitor changes and prevent excessive soil degradation by correcting negative (i.e., increasing) salinization trends.

\section{AUTHOR CONTRIBUTIONS}

ES and DC conceptualized the article. ES lead the writing effort. DC, RA, and TS contributed to the writing effort.

\section{FUNDING}

This study was supported by the United States Department of Agriculture-Agricultural Research Service, National Program 211: Water Availability and Watershed Management (project numbers 2036-61000-015-00 and 2036-61000-016-00).

Corwin, D. L. (2012). Field-scale monitoring of the long-term impact and sustainability of drainage water reuse on the west side of California's San Joaquin Valley. J. Environ. Monit. 14, 1576-1596. doi: 10.1039/c2em10796a

Corwin, D. L., Lesch, S. M., and Lobell, D. B. (2012). "Laboratory and field measurements," in Agricultural Salinity Assessment and Management. ASCE Manual and Reports on Engineering Practice no. 71, eds W. W. Wallender and K. K. Tanji (Reston, VA: ASCE), 295-341.

Fan, X., Liu, Y., Tao, J., and Weng, Y. (2015). Soil salinity retrieval from advanced multi-spectral sensor with partial least square regression. Remote Sens. 7, 488-511. doi: 10.3390/rs70100488

FAO and ITPS (2015). Status of the World's Soil Resources (SWSR). Main Report, Food and Agriculture Organization of the United Nations and Intergovernmental Technical Panel on Soils, Rome, Italy.

Goldshleger, N., Chudnovsky, A., and Ben-Binyamin, R. (2013). Predicting salinity in tomato using soil reflectance spectra. Int. J. Remote Sens. 34, 6079-6093. doi: 10.1080/01431161.2013.793859

Gomez, C., Oltra-Carrió, R., Bacha, S., Lagacherie, P., and Briottet, X. (2015). Evaluating the sensitivity of clay content prediction to atmospheric effects and degradation of image spatial resolution using Hyperspectral VNIR/SWIR imagery. Remote Sens. Environ. 164, 1-15. doi: 10.1016/j.rse.2015.02.019 
Han, W., Yang, Z., Di, L., and Mueller, R. (2012). CropScape: a Web service based application for exploring and disseminating US conterminous geospatial cropland data products for decision support. Comput. Electron. Agric. 84, 111-123. doi: 10.1016/j.compag.2012.03.005

Letey, J., Hoffman, G. J., Hopmans, J. W., Grattan, S. R., Suarez, D., Corwin, D. L., et al. (2011). Evaluation of soil salinity leaching requirement guidelines. Agric. Water Manage. 98, 502-506. doi: 10.1016/j.agwat.2010.08.009

Lobell, D. B. (2010). Remote sensing of soil degradation: introduction. J. Environ. Qual. 39, 1-4. doi: 10.2134/jeq2009.0326

Lobell, D. B., Lesch, S. M., Corwin, D. L., Ulmer, M. G., Anderson, K. A., Potts, D. J., et al. (2010). Regional-scale assessment of soil salinity in the Red River Valley using multi-year MODIS EVI and NDVI. J. Environ. Qual. 39, 35-41. doi: $10.2134 /$ jeq2009.0140

Lobell, D. B., Ortiz-Monasterio, J. I., Gurrola, F. C., and Valenzuela, L. (2007). Identification of saline soils with multiyear remote sensing of crop yields. Soil Sci. Soc. Am. J. 71, 777-783. doi: 10.2136/sssaj2006.0306

Maas, E., and Hoffman, G. (1977). Crop salt tolerancel-current assessment. J. Irrig. Drain. Div.103, 115-134.

McBratney, A. B., Santos, M. M., and Minasny, B. (2003). On digital soil mapping. Geoderma 117, 3-52. doi: 10.1016/S0016-7061(03)00223-4

Metternicht, G. (1998). Fuzzy classification of JERS-1 SAR data: an evaluation of its performance for soil salinity mapping. Ecol. Model. 111, 61-74.

Metternicht, G., and Zinck, J. (2003). Remote sensing of soil salinity: potentials and constraints. Remote Sens. Environ. 85, 1-20. doi: 10.1016/S00344257(02)00188-8

Miller, B. A., Koszinski, S., Wehrhan, M., and Sommer, M. (2015). Impact of multiscale predictor selection for modeling soil properties. Geoderma 239, 97-106. doi: 10.1016/j.geoderma.2014.09.018

Mougenot, B., Pouget, M., and Epema, G. (1993). Remote sensing of salt affected soils. Remote Sens. Rev. 7, 241-259. doi: 10.1080/02757259309532180

Mulla, D. J. (2013). Twenty five years of remote sensing in precision agriculture: key advances and remaining knowledge gaps. Biosyst. Eng. 11, 358-371. doi: 10.1016/j.biosystemseng.2012.08.009
Scudiero, E., Corwin, D. L., and Skaggs, T. H. (2015). Regional-scale soil salinity assessment using landsat ETM+ canopy reflectance. Remote Sens. Environ. 169, 335-343. doi: 10.1016/j.rse.2015.08.026

Tian, Y., Huffman, G. J., Adler, R. F., Tang, L., Sapiano, M., Maggioni, V., et al. (2013). Modeling errors in daily precipitation measurements: additive or multiplicative? Geophys. Res. Lett. 40, 2060-2065. doi: 10.1002/grl. 50320

Wu, W., Al-Shafie, W., Mhaimeed, A., Ziadat, F., Nangia, V., and Payne, W. (2014). Soil salinity mapping by multiscale remote sensing in mesopotamia, Iraq. IEEE J. Sel. Top. Appl. 7, 4442-4452. doi: 10.1109/jstars.2014.2360411

$\mathrm{Xu}$, C., Zeng, W., Huang, J., Wu, J., and van Leeuwen, W. J. (2016). Prediction of soil moisture content and soil salt concentration from hyperspectral laboratory and field data. Remote Sens. 8:42. doi: 10.3390/rs8010042

Zare, E., Huang, J., Santos, F., and Triantafilis, J. (2015). Mapping salinity in three dimensions using a DUALEM-421 and electromagnetic inversion software. Soil Sci. Soc. Am. J. 79, 1729-1740. doi: 10.2136/sssaj2015.06.0238

Zhang, T., Qi, J., Gao, Y., Ouyang, Z., Zeng, S., and Zhao, B. (2015). Detecting soil salinity with MODIS time series VI data. Ecol. Indic. 52, 480-489. doi: 10.1016/j.ecolind.2015.01.004

Zhang, T., Zeng, S., Gao, Y., Ouyang, Z., Li, B., Fang, C., et al. (2011). Using hyperspectral vegetation indices as a proxy to monitor soil salinity. Ecol. Indic. 11, 1552-1562. doi: 10.1016/j.ecolind.2011.03.025

Conflict of Interest Statement: The authors declare that the research was conducted in the absence of any commercial or financial relationships that could be construed as a potential conflict of interest.

Copyright (c) 2016 Scudiero, Corwin, Anderson and Skaggs. This is an open-access article distributed under the terms of the Creative Commons Attribution License (CC $B Y)$. The use, distribution or reproduction in other forums is permitted, provided the original author(s) or licensor are credited and that the original publication in this journal is cited, in accordance with accepted academic practice. No use, distribution or reproduction is permitted which does not comply with these terms. 